\title{
Chemistry of Metalated Container Molecules
}

Berthold Kersting

\section{1}

\section{Introduction}

Since the seminal work of Cram on cyclophanes and resorcinarenes [1] the hostguest chemistry of container molecules has been extensively investigated, and more sophisticated examples with other forms and larger cavities have been reported [2, 3]. Container molecules are of great interest, because their encapsulated guest species often exhibit novel and unusual properties which are not observed in the free or solvated state [4]. They are used today as probes of isolated molecules and of the intrinsic characteristics of the liquid state, and are capable of enantioselective recognition [5], reversible polymerization [6], isolation of reactive species [7], and promoting reactions within their interiors [8].

Several types of closed-shell host molecules with fascinating inner-phase binding and reactivity properties have been described in the literature [9]. These include covalently constructed molecular containers such as the carcerands [10], which encapsulate their guests irreversibly, and the calixarenes or resorcinarenes $[11,12]$, which have shell holes large enough to permit the exchange of guest molecules [13]. During the last two decades many examples of noncovalent molecular capsules formed by spontaneous aggregation via $\mathrm{H}$-bonds or metal-ligand coordinative bonds have also been described $[14,15]$.

In recent years, the development of metalated container molecules has become an attractive research goal [16-18] because such compounds allow for an interplay of molecular recognition and transition-metal catalysis [19, 20]. Consequently, a number of research groups are involved in the development of new receptor molecules that create confined environments about active metal coordination sites. In the following, selected types of metalated container molecules and their properties are briefly discussed. Thereafter, our work in this field is reported. 


\section{2}

\section{Metalated Container Molecules: A Brief Overview}

Metalated container molecules can be viewed as a class of compounds that have one or more active metal coordination sites within or next to a molecular cavity. Several host systems are capable of creating such structures. The majority of these compounds represent mononucleating ligand systems, as for instance calixarenes [21], cyclodextrines [22, 23], and some functionalized tripod ligands [24-26]. Figure 1.1 shows some representative examples. Coordination cages with active coordination sites are comparatively rare [27].
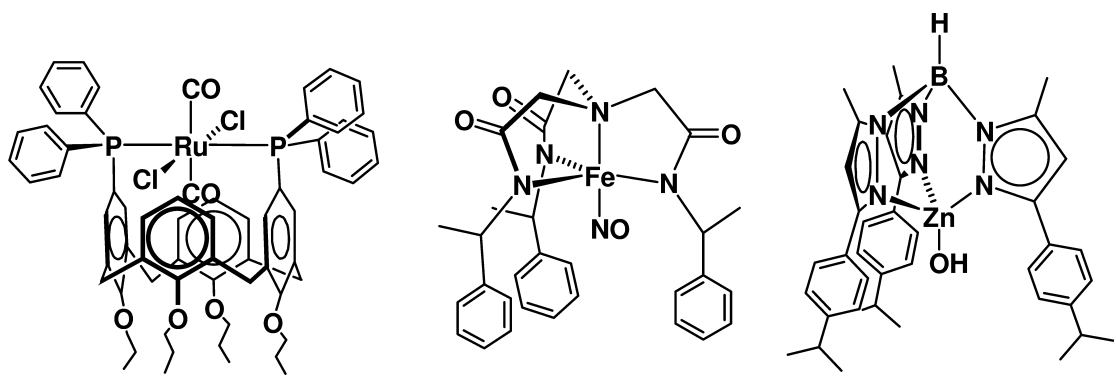

Figure 1.1 Structures of some mononucleating supporting ligands and their complexes [23-25].

Like their organic counterparts, metalated container molecules can not only stabilize reactive species or molecules in uncommon conformations [28] but also act as molecular reaction vessels for encapsulated substrates [29]. Moreover, they offer the advantage of stronger host-guest (substrate) interactions via coordinative bonds, thereby allowing activation and transformation of rather unreactive guest molecules [30, 31]. Complexes of functionalized ligand systems, in which the substituents serve to from a concave surface, have already been shown to exhibit enhanced chemical reactivity when compared with their unmodified analogs [32, 33]. They can be used as catalysts for selective organic transformations [20] and as catalysts for reactions which depend on the reaction medium [34]. Some complexes were also designed to mimic the hydrophobic binding site of metalloproteins [35]. The unusual properties can be traced back to complementary host-guest interactions and the distinct size and form of the binding cavities.

\section{3}

\section{Metalated Container Molecules of Binucleating Supporting Ligands}

Only a few ligand systems are known which impose cage-like structures about polynuclear core structures, and little is known about the chemistry of their corresponding complexes [36, 37]. These observations led us to study binuclear metal complexes with bowl-shaped binding cavities, hoping to modulate their chemical reactivity. In the following, we report the most important findings. 
1.3.1

\section{Synthesis}

We have been concerned with the development of binucleating supporting ligands for metalated container molecules for now about 6 years [38]. The 24-membered hexaaza-dithiophenolate ligand $\mathrm{H}_{2} \mathrm{~L}^{1}$ and its various derivatives (Scheme 1.1) were found to support such structures (see Section 1.3.2).

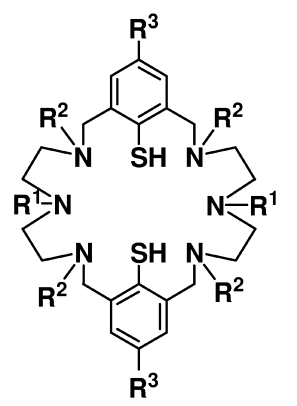

\begin{tabular}{llll} 
& $\mathrm{R}^{1}$ & $\mathrm{R}^{2}$ & $\mathrm{R}^{3}$ \\
\hline $\mathrm{H}_{2} \mathrm{~L}^{1}$ & $\mathrm{H}$ & $\mathrm{H}$ & $t \mathrm{Bu}$ \\
$\mathrm{H}_{2} \mathrm{~L}^{2}$ & $\mathrm{CH}_{3}$ & $\mathrm{CH}_{3}$ & $t \mathrm{Bu}$ \\
$\mathrm{H}_{2} \mathrm{~L}^{3}$ & $\mathrm{CH}_{3}$ & $\mathrm{H}$ & $t \mathrm{Bu}$ \\
$\mathrm{H}_{2} \mathrm{~L}^{4}$ & $\mathrm{CH}_{3}$ & $\mathrm{CH}_{3}$ & $\mathrm{H}$ \\
$\mathrm{H}_{2} \mathrm{~L}^{5}$ & $\mathrm{CH}_{3}$ & $\mathrm{CH}_{3}$ & $\mathrm{Ph}$ \\
$\mathrm{H}_{2} \mathrm{~L}^{6}$ & $\mathrm{CH}_{3}$ & $\mathrm{CH}_{3}$ & $\mathrm{C}_{6} \mathrm{H}_{4}-t \mathrm{Bu}$ \\
$\mathrm{H}_{2} \mathrm{~L}^{7}$ & $\mathrm{C}_{2} \mathrm{H}_{5}$ & $\mathrm{C}_{2} \mathrm{H}_{5}$ & $t \mathrm{Bu}$ \\
$\mathrm{H}_{2} \mathrm{~L}^{8}$ & $\mathrm{C}_{3} \mathrm{H}_{7}$ & $\mathrm{C}_{3} \mathrm{H}_{7}$ & $t \mathrm{Bu}$ \\
$\mathrm{H}_{2} \mathrm{~L}^{9}$ & $\mathrm{CH}_{3}$ & $\mathrm{C}_{2} \mathrm{H}_{5}$ & $t \mathrm{Bu}$ \\
$\mathrm{H}_{2} \mathrm{~L}^{10}$ & $\left(\mathrm{CH}_{2}\right)_{2} \mathrm{CN}$ & $\left(\mathrm{CH}_{2}\right)_{2} \mathrm{CN}$ & $t \mathrm{Bu}$ \\
$\mathrm{H}_{2} \mathrm{~L}^{11}$ & $\left(\mathrm{CH}_{2}\right)_{3} \mathrm{NH}_{2}$ & $\left(\mathrm{CH}_{2}\right)_{3} \mathrm{NH}_{2}$ & $t \mathrm{Bu}$ \\
$\mathrm{H}_{2} \mathrm{~L}^{12}$ & $\left(\mathrm{CH}_{2}\right)_{2} \mathrm{OCH}$ & $\left(\mathrm{CH}_{2}\right)_{2} \mathrm{OCH} \mathrm{H}_{3}$ & $t \mathrm{Bu}$ \\
$\mathrm{H}_{2} \mathrm{~L}^{13}$ & $\left(\mathrm{CH}_{2}\right)_{2} \mathrm{OH}$ & $\left(\mathrm{CH}_{2}\right)_{2} \mathrm{OH}$ & $t \mathrm{Bu}$
\end{tabular}

Scheme 1.1 Binucleating supporting ligands $\mathrm{H}_{2} \mathrm{~L}$.

The new ligands are obtained in good overall yields without the need of metal templates. Scheme 1.2 illustrates the general procedure. Reductive amination of tetraaldehyde 1 [39] with diethylene triamine under medium-dilution conditions affords the macrobicyclic hexaaza-dithioether 2 in excellent yields (>90\%) [40]. The aliphatic thioether linkage serves both as a protecting group for the air-sensitive thiophenolate groups and as a template function. It can be readily removed with $\mathrm{Na} / \mathrm{NH}_{3}$ to give the free ligands.

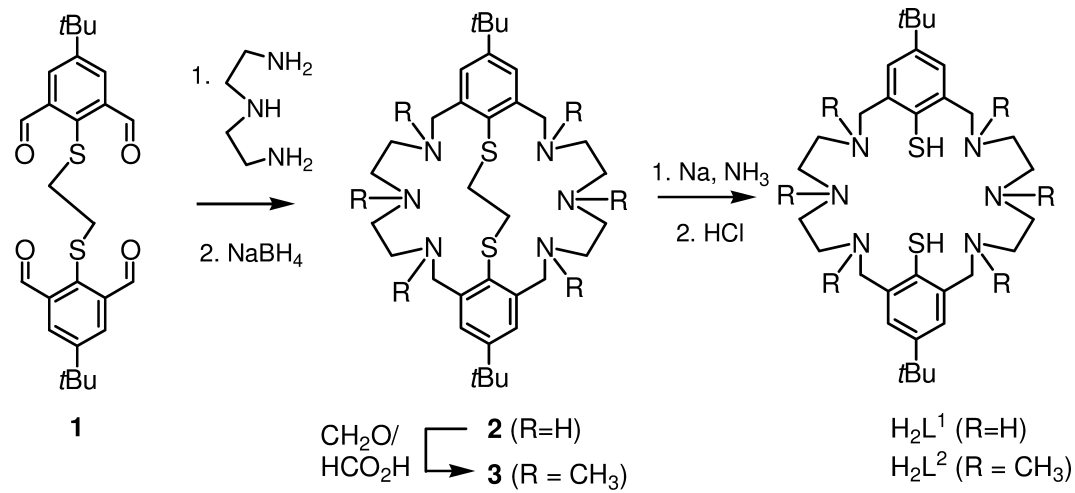

Scheme 1.2 Synthesis of $H_{2} L^{1}$ and $H_{2} L^{2}$.

An attractive feature of the macrobicycle 2 is that all of its six secondary amine functions are readily alkylated without affecting the masked thiolate functions. Thus, reductive methylation of $\mathbf{2}$ with formaldehyde and formic acid under 
Eschweiler-Clarke conditions yields the permethylated derivative 3 in nearly quantitative yield [41] (Scheme 1.2). Likewise $N$-alkyl substituents sterically more demanding than a methyl group $\left(\mathrm{H}_{2} \mathrm{~L}^{7}-\mathrm{H}_{2} \mathrm{~L}^{9}\right)$ can be readily introduced via acylation of 2 with the corresponding acid anhydrides (or acid chlorides) followed by $\mathrm{LiAlH}_{4}$ reduction of the resulting amides [42]. The protocol is also applicable for the synthesis of the derivatives $\mathrm{H}_{2} \mathrm{~L}^{4}-\mathrm{H}_{2} \mathrm{~L}^{6}$, which offer differing degrees of encapsulation due to their depth $\left(\mathrm{R}^{3}=\mathrm{H}[43], t \mathrm{Bu}, \mathrm{Ph}, 4-t \mathrm{Bu}\right.$ [44]). Moreover, compounds $\mathrm{H}_{2} \mathrm{~L}^{10}-\mathrm{H}_{2} \mathrm{~L}^{13}$ containing $\mathrm{R}^{1}$ and $\mathrm{R}^{2}$ side arms with terminal $\mathrm{CN}, \mathrm{OMe}, \mathrm{NH}_{2}$ and $\mathrm{OH}$ groups are also readily accessible [45].

The molecular structures of several of the hexaaza-dithioether intermediates have been determined by X-ray crystallography [43-47]. The macrobicycles adopt highly folded conformations, which are reminiscent of calixarenes [11] and related Schiffbase macrocycles [48, 49].

\subsection{2}

\section{Coordination Chemistry of Binucleating Supporting Ligands}

All ligands are effective dinucleating ligands that support the formation of bioctahedral $\left[\mathrm{M}_{2} \mathrm{~L}\left(\mathrm{~L}^{\prime}\right)\right]^{n+}$ complexes with a range of divalent and trivalent metal ions $\left(\mathrm{M}=\mathrm{Mn}^{\mathrm{II}}, \mathrm{Fe}^{\mathrm{II}}, \mathrm{Co}^{\mathrm{II}}, \mathrm{Ni}^{\mathrm{II}}, \mathrm{Zn}^{\text {II }}[42,50], \mathrm{Cd}^{\mathrm{II}}[51], \mathrm{Co}^{\mathrm{III}}[52]\right)$. Table 1.1 lists a selection of the synthesized complexes and their labels. The macrocycles adopt either a $C_{2 v^{-}}$ symmetric 'bowl-shaped' conformation of type B or a $C_{\mathrm{s}}$-symmetric 'saddle-shaped' conformation of type A (Figure 1.2). The former is observed for multi-atom coligands

Table 1.1 Selected complexes, their labels and structures. ${ }^{\text {a) }}$

\begin{tabular}{|c|c|c|c|c|}
\hline Complex & & Structure & {$[\mathrm{d}(\mathrm{M} \cdots \mathrm{M}) / \AA ̊ \AA]$} & Ref. \\
\hline 4 & {$\left[\mathrm{Ni}^{\mathrm{II}}{ }_{2} \mathrm{~L}^{1}(\mu-\mathrm{Cl})\right]^{+}$} & $\mathrm{A}$ & $3.098(2)$ & {$[41]$} \\
\hline 5 & {$\left[\mathrm{Co}_{2}{ }_{2} \mathrm{~L}^{1}(\mu-\mathrm{Cl})\right]^{+}$} & n.d. ${ }^{b)}$ & & {$[40]$} \\
\hline 6 & {$\left[\mathrm{Ni}^{\mathrm{II}}{ }_{2} \mathrm{~L}^{2}(\mu-\mathrm{Cl})\right]^{+}$} & $\mathrm{A}$ & $3.184(1)$ & [41] \\
\hline 7 & {$\left[\mathrm{Co}^{\mathrm{II}}{ }_{2} \mathrm{~L}^{2}(\mu-\mathrm{Cl})\right]^{+}$} & A & $3.165(1)[3.194(1)]^{c)}$ & [54] \\
\hline 8 & {$\left[\mathrm{Ni}^{\mathrm{II}}{ }_{2} \mathrm{~L}^{3}(\mu-\mathrm{Cl}]^{+}\right.$} & $\mathrm{A}$ & $3.074(1)$ & [47] \\
\hline 9 & {$\left[\mathrm{Ni}^{\mathrm{II}}{ }_{2} \mathrm{~L}^{9}(\mu-\mathrm{Cl}]^{+}\right.$} & $\mathrm{A}$ & $3.2400(4)$ & [47] \\
\hline 10 & {$\left[\mathrm{Mn}^{\mathrm{II}}{ }_{2} \mathrm{~L}^{2}(\mu-\mathrm{OAc})\right]^{+}$} & $\mathrm{B}$ & $3.456(1)$ & {$[50]$} \\
\hline 11 & {$\left[\mathrm{Fe}^{\mathrm{II}}{ }_{2} \mathrm{~L}^{2}(\mu-\mathrm{OAc})\right]^{+}$} & B & $3.421(1)$ & {$[50]$} \\
\hline 12 & {$\left[\mathrm{CO}_{2}{ }_{2} \mathrm{~L}^{2}(\mu-\mathrm{OAc})\right]^{+}$} & $\mathrm{B}$ & $3.448(1)$ & {$[50,52]$} \\
\hline 13 & {$\left[\mathrm{Ni}^{1 \mathrm{II}}{ }_{2} \mathrm{~L}^{2}(\mu-\mathrm{OAc})\right]^{+}$} & $\mathrm{B}$ & $3.483(1)$ & {$[50,54]$} \\
\hline $14 b$ & {$\left[\mathrm{Zn}^{\mathrm{II}}{ }_{2} \mathrm{~L}^{2}(\mu-\mathrm{OAc})\right]^{+}$} & B & $3.427(1)$ & [54] \\
\hline 15 & {$\left[\mathrm{Co}_{2}{ }_{2}^{11} \mathrm{~L}^{8}(\mu-\mathrm{OAc})\right]^{+}$} & B & $3.482(1)$ & [42] \\
\hline 16 & {$\left[\mathrm{Zn}_{2}{ }_{2}^{\mathrm{I}} \mathrm{L}^{8}(\mu-\mathrm{OAc})\right]^{+}$} & B & $3.460(1)$ & {$[42]$} \\
\hline 17 & {$\left[\mathrm{Ni}^{11}{ }_{2} \mathrm{~L}^{8}(\mu-\mathrm{OAc})\right]^{+}$} & B & $3.513(1)$ & {$[42]$} \\
\hline 18 & {$\left[\mathrm{Ni}^{\mathrm{iI}}{ }_{2} \mathrm{~L}^{2}(\mu-\mathrm{OH})\right]^{+}$} & A & $3.037(3)$ & {$[41]$} \\
\hline
\end{tabular}

a) The complexes were isolated as $\mathrm{ClO}_{4}{ }^{-}$or $\mathrm{BPh}_{4}{ }^{-}$salts.

b) Not determined.

c) There are two independent molecules in the unit cell. Value in square brackets corresponds to the second molecule. 
$\mathrm{L}^{\prime}$, the latter for single-atom bridges [41, 40]. Complexes of type B are amongst the first prototypes for binuclear complexes with confined binding cavities [53]. The two aromatic rings of $\mathrm{H}_{2} \mathrm{~L}$ form the walls of the binding pockets.
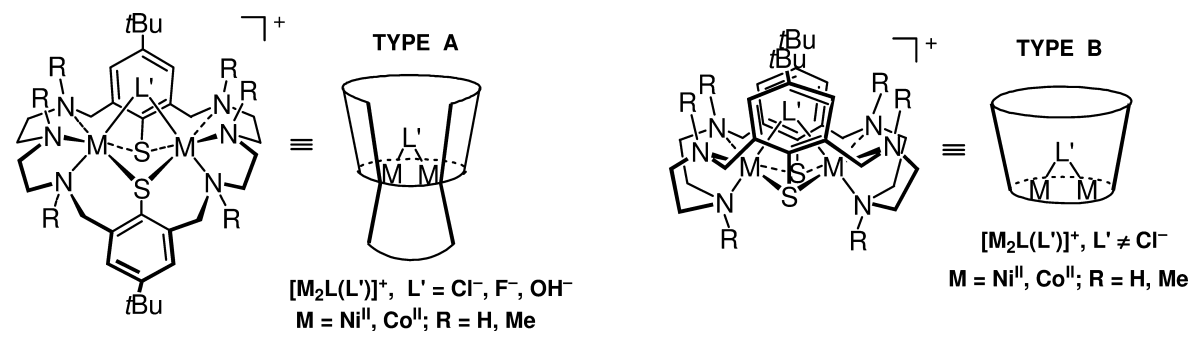

Figure 1.2 Structures of complexes of binucleating supporting ligands $\mathrm{H}_{2} \mathrm{~L}^{1}$ and $\mathrm{H}_{2} \mathrm{~L}^{2}$. The cavity representation used should not be confused with the one used for cyclodextrins [34].

\subsection{3}

\section{Effects of $\mathrm{N}$-alkylation on the Molecular and Electronic Structures of the Complexes}

It is well established that the molecular and electronic structures of metal complexes of azamacrocycles are affected upon $N$-alkylation. This is mainly due to two factors: (i) the decrease in the ligand field strength and (ii) the increase in the steric requirements upon going from a secondary to a tertiary amine donor function [55]. In order to examine whether the properties of our complexes are affected by the $\mathrm{N}$-alkyl substituents, we have characterized analogous complexes of the two macrocycles $\mathrm{H}_{2} \mathrm{~L}^{1}$ and $\mathrm{H}_{2} \mathrm{~L}^{2}$ by various spectroscopic methods (IR, UV/Vis, EPR, ${ }^{57} \mathrm{Fe}-\mathrm{Möss} b a u e r$ spectroscopy), cyclic voltammetry, temperature-dependent magnetic susceptibility measurements and X-ray crystallography. The most important findings of these investigations are as follows:

- The conversion of the six secondary into tertiary amine donor functions does not change the overall structure of the $\left[\mathrm{M}_{2} \mathrm{~L}\left(\mathrm{~L}^{\prime}\right)\right]$ complexes. That is, the macrocycle conformation remains constant for a given coligand [41]. This offers the opportunity to extend the rims of the binding pocket of the $\left[\mathrm{M}_{2} \mathrm{~L}\left(\mathrm{~L}^{\prime}\right)\right]$ complexes.

- Complexes of the peralkylated macrocycles exhibit longer M-N and shorter M-L' bond distances than the homologous complexes of the parent compound $\left(\mathrm{L}^{1}\right)^{2-}$ [47]. In other words, $N$-functionalization leads to stronger metal-coligand bonding interactions, which in turn results in a stronger polarization of the bridging coligands and thus in higher reactivity of the complexes.

- The $N$-alkylated supporting ligands generate a more hydrophobic cavity about the active coordination site. The NH functions in 4, for example, are involved in interand intra-molecular hydrogen bonding interactions, whereas no such interactions are observed for $\mathbf{6}$. This drastically alters the ease of the substitution of the bridging coligands. Thus, while the latter complex reacts readily with $\mathrm{NBu}_{4} \mathrm{OH}$ in 
acetonitrile to produce the hydroxo-bridged complex 18, the former complex was found to be unreactive [41].

- The donor strength of $\mathrm{H}_{2} \mathrm{~L}^{2}$ is significantly weaker (by ca. $650 \mathrm{~cm}^{-1}$ ) than its unmodified derivative as determined by UV/Vis spectroscopy [41]. The different ligand field strengths are also reflected in the redox potentials. In the $\left[\mathrm{M}_{2} \mathrm{~L}^{2}\left(\mathrm{~L}^{\prime}\right)\right]$ complexes the $\mathrm{M}^{\mathrm{III}}$ oxidation state is enormously destabilized compared with the $\mathrm{M}^{\mathrm{II}}$ oxidation state, even in the case of $\mathrm{Co}[38,52]$. As a consequence of the weak ligand field of $\left(\mathrm{L}^{2}\right)^{2-}$, the $\mathrm{Mn}^{\mathrm{II}}, \mathrm{Fe}^{\mathrm{II}}, \mathrm{Co}^{\mathrm{II}}$ and $\mathrm{Ni}^{\mathrm{II}}$ ions in the acetato-bridged complexes 10-13 adopt high-spin configurations [50].

Overall, the use of the permethylated derivative $\mathrm{H}_{2} \mathrm{~L}^{2}$ in place of $\mathrm{H}_{2} \mathrm{~L}^{1}$ influences many properties of the binuclear $\left[\mathrm{M}_{2} \mathrm{~L}\left(\mathrm{~L}^{\prime}\right)\right]^{+}$complexes, including color, molecular and electronic structure, hydrogen bonding interactions, redox potential, complex stability, and ground spin-state. The reactivity is also greatly affected (see Section 1.3.5).

\subsection{4}

\section{The Ligand Matrix as a Medium}

A series of zinc complexes (14) bearing different carboxylate coligands were prepared and characterized by NMR spectroscopy in solution (Table 1.2). The most important findings of these investigations are as follows:

- All complexes exist as discrete species in solution.

- The NMR signals of the coligands are shifted downfield from their values in the uncomplexed form $[47,51,56]$. The shift to higher field can be explained by the ring current effect. The coligands are located above the center of the two aryl rings of $\left(L^{2}\right)^{2-}$ in the shielding region [57]. This results in the observed chemical shift change to higher field. It clearly indicates that the ligand matrix functions as a medium.

- Ligand exchange reactions of the zinc complexes are rapid (Scheme 1.3). The equilibrium concentrations of the individual species are attained within the time scale of sample preparation $(<30 \mathrm{~s})$.

Table 1.2 Carboxylato-bridged zinc complexes 14a-14f.

\begin{tabular}{|c|c|c|c|c|c|}
\hline Complex & & Coligand & Structure & $\mathrm{p} K_{\mathrm{s}}$ & $K_{\text {rel }}$ \\
\hline $14 a$ & {$\left[\mathrm{Zn}_{2}{ }_{2} \mathrm{~L}^{2}\left(\mathrm{O}_{2} \mathrm{CH}\right)\right]^{+}$} & Formate & B & 3.75 & 0.1 \\
\hline $14 b$ & {$\left[\mathrm{Zn}_{2}{ }_{2} \mathrm{~L}^{2}\left(\mathrm{O}_{2} \mathrm{CCH}_{3}\right)\right]^{+}$} & Acetate & B & 4.75 & 1.0 \\
\hline $14 \mathrm{c}$ & {$\left[\left(\mathrm{Zn}_{2}{ }_{2} \mathrm{~L}^{2}\left(\mathrm{O}_{2} \mathrm{CCH}_{2} \mathrm{Cl}\right)\right]^{+}\right.$} & Chloroacetate & $\mathrm{B}$ & 2.86 & 1.1 \\
\hline $14 d$ & {$\left[\mathrm{Zn}_{2}{ }_{2} \mathrm{~L}^{2}\left(\mathrm{O}_{2} \mathrm{CCH}_{2} \mathrm{CH}_{3}\right)\right]^{+}$} & Propionate & B & 4.87 & 2.7 \\
\hline $14 \mathrm{e}$ & {$\left[\mathrm{Zn}^{\mathrm{II}}{ }_{2} \mathrm{~L}^{2}\left(\mathrm{O}_{2} \mathrm{CC}_{6} \mathrm{H}_{5}\right)\right]^{+}$} & Benzoate & B & 4.20 & 5.4 \\
\hline $14 f$ & {$\left[\mathrm{Zn}_{2}^{\mathrm{II}} \mathrm{L}^{2}\left(\mathrm{O}_{2} \mathrm{CC}_{6} \mathrm{H}_{4}-p-\mathrm{CH}_{3}\right)\right]^{+}$} & 4-Methyl benzoate & $\mathrm{B}$ & 4.38 & 9.0 \\
\hline
\end{tabular}




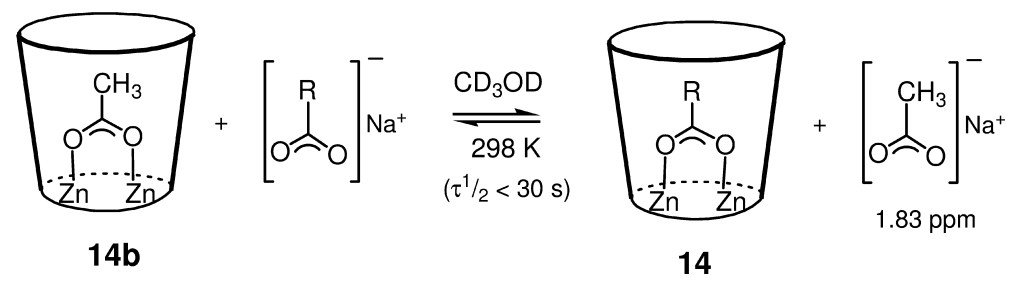

Scheme 1.3 Exchange of carboxylate ligands in dizinc complexes 14 .

In order to probe the hydrophobicity of the binding cavity of the $\left[\mathrm{Zn}_{2} \mathrm{~L}^{2}\right]^{2+}$ fragment [58], the relative stability constants $\left(K_{\text {rel }}\right)$ of the carboxylato-bridged zinc complexes were determined [59]. The concentrations of the species were measured by integration of the respective NMR signals and the relative stability constants were determined with the mass action law. Table 1.2 lists the so calculated values. As can be seen, the stability constants differ by about two orders of magnitude and are not correlated with the $\mathrm{p} K_{\mathrm{a}}$ values of the acids. Rather, they increase in the order $\mathbf{1 4 a}<\mathbf{1 4 b}<\mathbf{1 4} \mathrm{c}<\mathbf{1 4 d}<\mathbf{1 4} \mathrm{e}<\mathbf{1 4 f}$. Thus, the larger the organic residue $\mathrm{R}$ of the carboxylate anion $\left(\mathrm{RCO}_{2}{ }^{-}\right)$the larger is the binding constant. The observed trend is indicative of hydrophobic effects (Van der Waals interactions) between the substituents of the carboxylate ion and the macrocyclic ligand. These interactions contribute to the stability of the complexes.

\section{3 .5}

\section{Variation, Coordination Modes and Activation of Coligands}

The coordination chemistry of transition-metal complexes with well-defined binding pockets is of interest in many respects. In particular, by adjusting the size and form of the pocket it is often possible to stabilize reactive intermediates or to coordinate coligands in unusual coordination modes. Such assemblies also offer the opportunity to study secondary host-guest interactions between the coordinated coligands and the walls of the host [60]. For systematic investigations it is of importance that various coligands can be accommodated in the binding pocket of the container molecules. Single crystals suitable for X-ray structure determinations are also required such that one can study the effects of the size and form of the binding pocket on the coordination mode of the coligands and vice versa.

In this context it is to be noted that a large number of coligands can be readily accommodated in the binding pocket of the $\left[\mathrm{M}^{\mathrm{II}}{ }_{2} \mathrm{~L}^{2}\right]^{2+}$ fragments [86]. These include $\mathrm{Cl}^{-}$[41], $\mathrm{OH}^{-}$[40], $\mathrm{NO}_{2}{ }^{-}, \mathrm{NO}_{3}{ }^{-}, \mathrm{N}_{3}^{-}$[61], $\mathrm{BH}_{4}^{-}$[62], various carboxylates and alkylcarbonates [43, 52, 63], $\mathrm{N}_{2} \mathrm{H}_{4}$, pyrazolate, pyridazine [61], $\mathrm{H}_{2} \mathrm{PO}_{4}{ }^{-}$[54], $\mathrm{SH}^{-}$[64] and some biologically relevant molecules such as $\mathrm{HCO}_{3}{ }^{-}$[54], $\left(p-\mathrm{NO}_{2} \mathrm{C}_{6} \mathrm{H}_{4} \mathrm{O}\right)_{2} \mathrm{PO}_{2}{ }^{-}$ and proline [64], to name but a few. Single crystals of X-ray quality were obtained in each case.

More recent examples of metalated container molecules are 20-22 with classical $[65,66]$ or organometallic metallo coligands (Scheme 1.4) [64]. Such compounds 
are readily accessible from the labile $\mathrm{ClO}_{4}{ }^{-}$complexes 19a,b [65]. They are stable in a range of organic solvents, and their charged nature gives them good solubility.

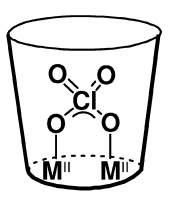

$19 \mathbf{a}(\mathrm{M}=\mathrm{Ni})$

$\mathrm{Ni} \cdots \mathrm{Ni} 3.547(1) \AA$ $v_{3}\left(\mathrm{ClO}_{4}\right) 1113,1097 \mathrm{~cm}^{-1}$

$19 \mathrm{~b}(\mathrm{M}=\mathrm{Co})$ $v_{3}\left(\mathrm{ClO}_{4}\right) 1113,1097 \mathrm{~cm}^{-1}$
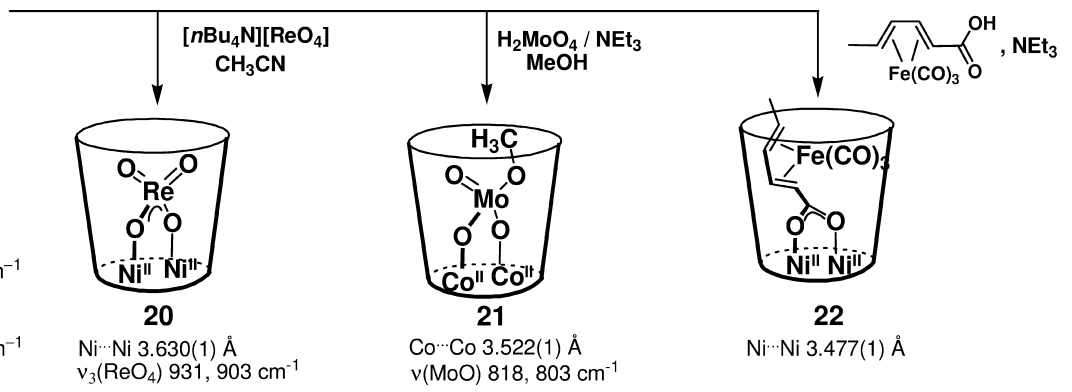

Scheme 1.4 Preparation of complexes 20-22.

$\mathrm{Ni} \cdots \mathrm{Ni} 3.477(1) \AA$

The binding modes of the coligands in the complexes 23-25 merit further consideration (Scheme 1.5). The hydrazine complex 23 provides an example of an unusual conformation of a small inorganic molecule. Free hydrazine exists predominantly in the gauche conformation at room temperature (dihedral angle $\tau \sim 100^{\circ}$ ) [67]. In 23, a cis (ecliptic) conformation $\left(\tau=3.7^{\circ}\right)$ is observed. This conformation is presumably enforced by repulsive $\mathrm{NH} \cdots \mathrm{C}_{\text {aryl }}$ van der Waals interactions [68]. In 24, an unusual conformation of an organic molecule is present [43]. The substituents in cyclohexene rings generally assume equatorial positions. In 24 , they are axial. The container molecules can also stabilize resonance extremes. Complex 25, bearing a $p$-nitrophenolate in the quinoid aci-form is an example [69]. This clearly shows that $\left[\mathrm{M}_{2} \mathrm{~L}\right]$ complexes can accommodate guest molecules in unusual coordination modes.

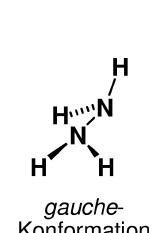

$\left(\tau \sim 100^{\circ}\right)$

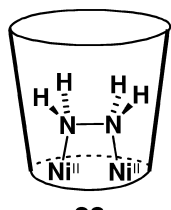

23

$\mathrm{Ni} \cdots \mathrm{Ni} 3.441(1) \AA$ $\left(\tau=3.7^{\circ}\right)$

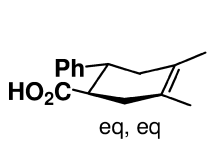

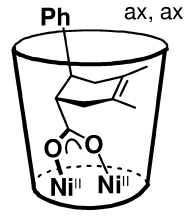

24

Scheme 1.5 Binding mode of the coligands in 23-25.
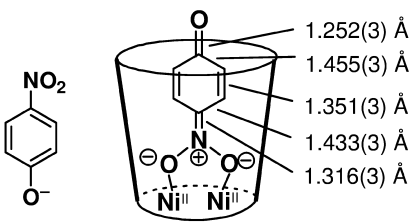

25

$\mathrm{Ni} \cdots \mathrm{Ni} 3.494(1) \AA$

Finally, reactive molecules can also be incorporated in the binding cavities. The $\mathrm{BH}_{4}{ }^{-}$complex 26 is an example (Scheme 1.6). In the absence of air and protic reagents this compound is stable for weeks both in the solid state and in solution [62]. This stability is quite remarkable given that nickel(II) complexes of sterically less demanding ligands are readily reduced to nickel boride. The $\mathrm{BH}_{4}{ }^{-}$becomes activated upon coordination as indicated by IR by the shifts of the B-H stretching frequencies 
(Figure 1.3). The complex reacts rapidly with protic reagents $\left(\mathrm{HCl}, \mathrm{H}_{2} \mathrm{O}\right)$, with electrophiles $\left(\mathrm{CO}_{2}, \mathrm{~S}_{8}\right)$ and halogenated solvents $\left(\mathrm{CCl}_{4}\right)$.

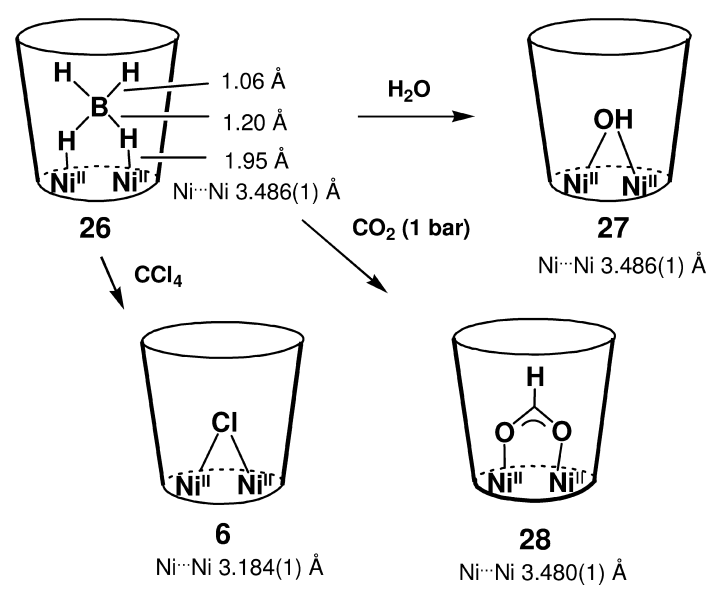

Scheme 1.6 Reactions of 26.

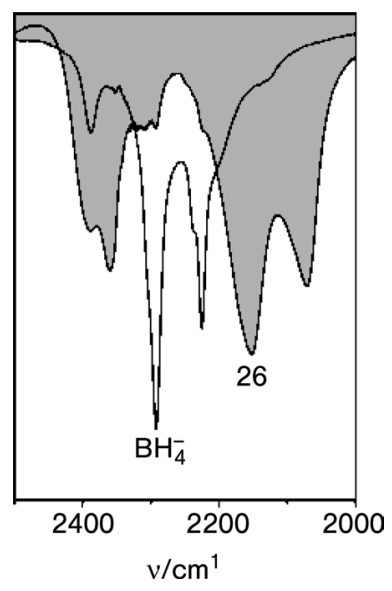

Figure 1.3 IR spectrum of 26 .

In summary, a large number of coligands can be accommodated in the binding pockets of the $\left[\mathrm{M}_{2} \mathrm{~L}\right]^{2+}$ complexes. In each case only one of several possible coordination modes of the coligand is realized. In some cases, the binding pocket confers very unusual coordination modes or conformations on the guest molecules. Stabilization and activation of reactive molecules is observed in other instances. Since the complex integrity is retained in the solution state, the reactivity of these compounds can be examined (see below). 
It has already been mentioned that utilization of the permethylated ligand $\left(\mathrm{L}^{2}\right)^{2-}$ in place of $\left(\mathrm{L}^{1}\right)^{2-}$ drastically alters the ease of substitution reactions of the $\left[\mathrm{M}_{2} \mathrm{~L}(\mathrm{Cl})\right]^{+}$ complexes (Section 1.3.2). Further studies revealed a remarkable influence of the hydrophobic pocket on the rate and course of several substrate transformations, including for example the fixation of carbon dioxide [54] and the cis-bromination of $\alpha, \beta$-unsaturated carboxylate ligands [63] (Scheme 1.7).

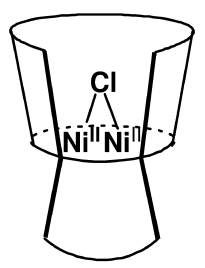

6

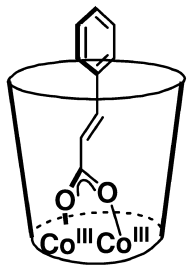

30
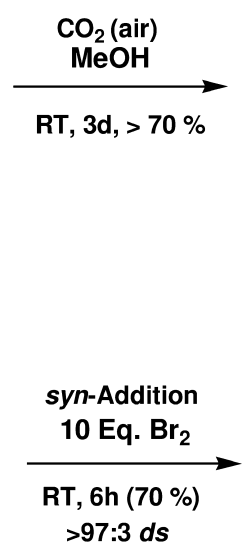

$>97: 3 \mathrm{ds}$

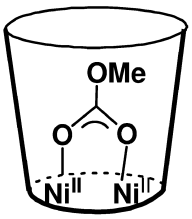

29

$\mathrm{Ni} \cdots \mathrm{Ni} 3.491(1) \AA$

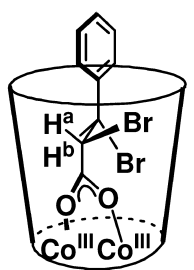

31

Scheme 1.7 Fixation of $\mathrm{CO}_{2}$ and cis-bromination of $\alpha, \beta$-unsaturated carboxylate ligands.

Recently, it has been found that the outcome of some cycloadditions can be altered remarkably when they are performed inside the cavity of cyclodextrines [70], selfassembled molecular capsules [71], or coordination cages [72]. This fact intrigued us greatly and awoke our interest in the Diels-Alder reactivity of the 'calixarene-like' $\left[\mathrm{M}_{2} \mathrm{~L}^{2}\left(\mathrm{~L}^{\prime}\right)\right]^{+}$complexes bearing unsaturated carboxylate coligands $\mathrm{L}^{\prime}$ [43]. The results are discussed in more detail.

The observation that $\alpha, \beta$-unsaturated carboxylate ligands can be readily incorporated led us to study an orienting reaction between 35 and 2,3-dimethylbutadiene (33). The free reaction proceeds readily in toluene solution to give the adduct 34 (Scheme 1.8). However, the reaction of 35 with a large excess of 33 did not occur, even when heated at $210^{\circ} \mathrm{C}$ for $24 \mathrm{~h}$. The inhibition of the Diels-Alder reaction can be traced to the limited space in the binding pocket of 35 .

The above findings prompted us to study the reaction between a coordinated dienoate ligand and an external alkene. The reaction between sorbinic acid and acrylonitrile was selected (Scheme 1.9). This reaction is rather slow (pseudo-firstorder rate constant $k^{\prime}=4.8 \times 10^{-6} \mathrm{~s}^{-1}, \tau_{1 / 2} \approx 2$ days) and produces a mixture of the

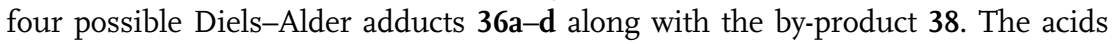


<smiles>O=C(O)C=Cc1ccccc1</smiles>

32

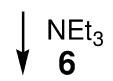

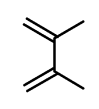

33

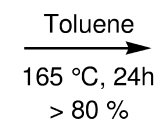

$>80 \%$<smiles>O=C[C@H]1CC=CCC1P</smiles>

34

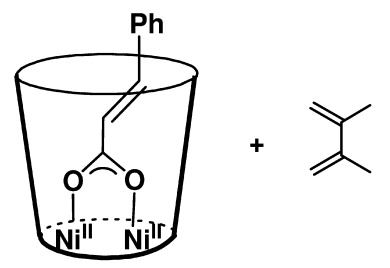

35

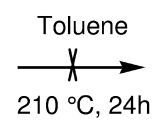

$210^{\circ} \mathrm{C}, 24 \mathrm{~h}$

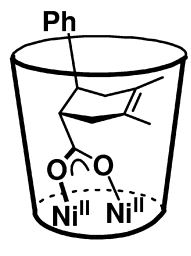

24

Scheme 1.8 Preparation of 34,35 and 24.

isomerize under the basic reaction conditions to give the $\alpha, \beta$-unsaturated derivatives 37a-d.

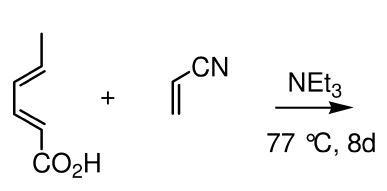<smiles>C/C=C/C=C/C(=O)OCCC#N</smiles>

$38(5 \%)$

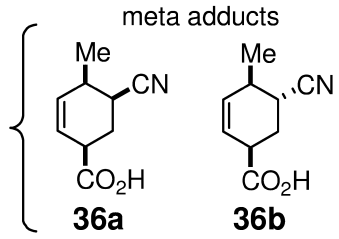

(exo) ortho adducts<smiles>C[C@H]1C=CC(C(=O)O[Na])C(C#N)C1</smiles>

(endo)<smiles>CC1C=CC(C(=O)O)C(CCCCOC(=O)O)C1</smiles>

(exo)

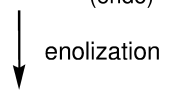<smiles>[C]C1CC=C(C(=O)O)CC1C#N</smiles>

37 a (40\%) 37b (28\%)<smiles>CC1CC=C(C(=O)O)CC1C#N</smiles><smiles>CC1CC=C(C(=O)O)C(C#N)C1</smiles><smiles>CC1CC=C(C(=O)O)C(C#N)C1</smiles>

37c (19\%) 37d (7\%)

Scheme 1.9 Preparation of 36-38. Numbers in parentheses refer to yields of isolated products.

Thereafter, the reaction between the coordinated dienoate ligand in $\mathbf{3 9}$ and acrylonitrile was examined (Scheme 1.10). Surprisingly, this reaction completes within $56 \mathrm{~h}$ (pseudo-first-order rate constant $k^{\prime}=1.4 \times 10^{-5} \mathrm{~s}^{-1}, \tau_{1 / 2} \approx 0.5$ days) and affords only two products, $4 \mathbf{a}$ and $\mathbf{4 0 \mathbf { b }}$, in a ratio of $57: 43$. The products $3 \mathbf{6 a}, \mathbf{b}$ can be liberated via acid hydrolysis. Thus, in striking contrast to the low regioselectivity observed in the background reaction, the Diels-Alder reaction between the encapsulated dienoate and acrylonitrile proceeds with strict 'meta' regioselectivity. In addition, no by-products are detected. 
12| 1 Chemistry of Metalated Container Molecules

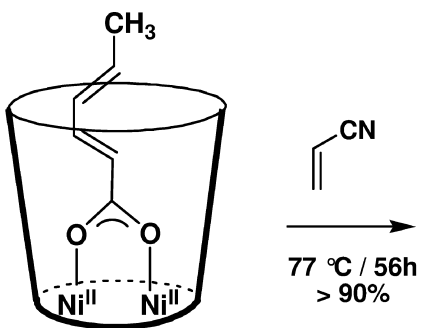

39

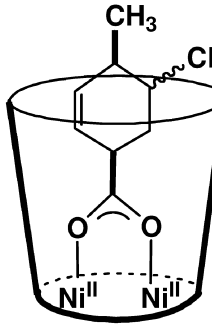

$40 a, b$

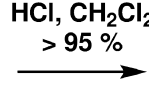

Scheme 1.10 Preparation of complexes 40a,b and Diels-Alder products $36 \mathrm{a}, \mathrm{b}$

This and the fact that the Diels-Alder adducts 36a,b do not isomerize in the binding pocket of the complexes can be attributed to the directing and protecting effect of the binding cavity as schematically represented in Scheme 1.11.

\section{Regioselectivity}

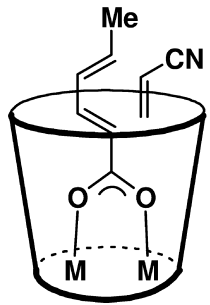

Diels-Alder Selectivity

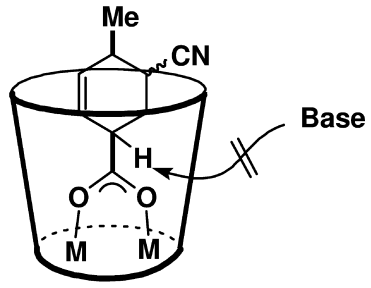

Scheme 1.11 Directing and protecting effect of the binding cavity.

Similar results were obtained for analogous complexes of the de-tert-butylated macrocycle $\left(\mathrm{L}^{3}\right)^{2-}[43]$. The tert-butyl substituents do not affect the regiochemistry of this particular Diels-Alder reaction, but they clearly increase its rate. The observed trend is indicative of a small stabilization of the transition-state by hydrophobic effects $\left(\Delta \Delta G^{\ddagger} \approx 3 \mathrm{~kJ} / \mathrm{mol} ; k_{\text {complex }}^{\prime} / k_{\text {background }}^{\prime}=\exp \left(\Delta \Delta G^{\ddagger} / R T\right)\right)$. This would be consistent with our earlier observation that complexes bearing less polar carboxylate anions have the higher stability constants (see Section 1.3.4). Overall, the reaction between the coordinated sorbinate coligand and acrylonitrile is controlled by the binding cavity of the complexes and is highly regioselective. The new method is currently only applicable to dienes with anchoring carboxylate groups, but expansion of this approach to a general concept for the control of the regioselectivity of Diels-Alder reactions between unsymmetrical dienes and dienophiles appears to be within reach.

\section{4}

\section{Conclusions}

The development, synthesis, and coordination chemistry of novel metal complexes with deep binding cavities have been described. It was demonstrated that the doubly 
deprotonated forms of the macrocycles $(\mathrm{L})^{2-}$ support the formation of complexes of the type $\left[\mathrm{M}_{2} \mathrm{~L}\left(\mathrm{~L}^{\prime}\right)\right]$ with bowl-shaped, 'calixarene-like' structures. The compounds are amongst the first prototypes for metalated container molecules with open binding cavities. Despite the fact that the active coordination site $\mathrm{L}^{\prime}$ is deeply buried in the center of the molecules, it is readily accessible for a wide range of exogenous guest molecules. A large number of crystal structure determinations have provided insights into the binding modes of the coligands. These sense the size and form of the binding pocket of the $\left[\mathrm{M}_{2} \mathrm{~L}\right]^{2+}$ fragments, as indicated by distinctive binding modes and unusual conformations. The use of the $N$-alkylated macrocycles in place of the unmodified analogs influences many properties of the binuclear complexes, including color, molecular and electronic structure, hydrogen bonding interactions, redox potential, complex stability, and ground spin-state. The reactivity is also greatly affected as shown by the activation and transformation of small molecules such as $\mathrm{CO}_{2}$, the highly diastereoselective cis-bromination of $\alpha, \beta$-unsaturated carboxylate coligands, and some regioselective Diels-Alder reactions.

\section{Acknowledgments}

Several coworkers named on our joint publications have made major contributions to the chemistry described here. This chemistry would not have reached its current level of broad synthetic utility without their dedication. I am particularly thankful for Prof. H. Vahrenkamp for providing facilities for spectroscopic and X-ray crystallographic measurements. Financial assistance by the Deutsche Forschungsgemeinschaft (SPP 1118, 'Sekundäre Wechselwirkungen'), the University of Freiburg, and the University of Leipzig is gratefully acknowledged.

\section{References}

1 Cram, D.J. and Cram, J.M. (1994) Container Molecules and their Guests, Royal Society of Chemistry, Cambridge.

2 Oshovsky, G.V., Reinhoudt, D.N. and Verboom, W. (2007) Angewandte ChemieInternational Edition, 46, 2366-2393.

3 Rissanen, K. (2005) Angewandte Chemie International Edition, 44, 3652-3654.

4 Hecht, S. and Fréchet, J.M.J. (2001) Angewandte Chemie - International Edition, 40, 74-91.

5 Rivera, J.M., Martin, T. and Rebek, J., Jr (1998) Science, 279, 1021-1023.

6 Ritter, H., Sadowski, O. and Tepper, E. (2003) Angewandte Chemie - International Edition, 42, 3171-3173.
7 (a) Warmuth, R., Kerdelhué, J.-L. Carrera, S.S., Langenwalter, K.J. and Brown, N. (2002) Angewandte Chemie - International Edition, 41, 96-99. (b) Roach, P. and Warmuth, R. (2003) Angewandte Chemie - International Edition, 42, 3039-3042.

8 (a) Hof, F., Craig, S.L., Nuckolls, C. and Rebek, J., Jr (2002) Angewandte Chemie International Edition, 41, 1488-1508.

(b) Hof, F., Craig, S.L., Nuckolls, C. and Rebek, J., Jr (2005) Angewandte Chemie International Edition, 44, 2068-2078.

9 (a) Vögtle, F. (1992) Supramolekulare Chemie, Teubner, Stuttgart. (b) Lehn, J.M. (1995) Supramolecular Chemistry, John 
Wiley \& Sons, Chichester. (c) Steed, J.W. and Atwood, J.L. (2000) Supramolecular Chemistry, John Wiley \& Sons, Chichester.

10 Cram, D.J., Tanner, M.E. and Thomas, R. (1991) Angewandte Chemie - International Edition, 30, 1024-1027.

11 Gutsche, C.D. (1998) Calixarenes, Revisited, Royal Society of Chemistry, Hertforshire.

12 McKinlay, R.M. and Atwood, J.L. (2007) Angewandte Chemie - International Edition, 46, 2394-2397.

13 Lützen, A. (2005) Angewandte Chemie International Edition, 44, 1000-1002.

14 Yoshizawa, M., Tamura, M. and Fujita, M. (2006) Science, 312, 251-254.

15 Fujita, M., Tominga, M., Hori, A. and Therrrien, B. (2005) Accounts of Chemical Research, 38, 371-398.

16 Canary, J.W. and Gibb, B.C. (1997) Progress in Inorganic Chemistry, 45, 1-83.

17 Armspach, D. and Matt, D. (1999) Chemical Communications, 1073-1074.

18 Cameron, B.R., Loeb, S.J. and Yap, G.P.A. (1997) Inorganic Chemistry, 36, 5498-5504.

19 Molenveld, P., Engbersen, J.F.J. and Reinhoudt, D.N. (2000) Chemical Society Reviews, 29, 75-86.

20 (a) Reetz, M.T. and Waldvogel, S.R. (1997) Angewandte Chemie (International Edition in English), 36, 865-867. (b) Reetz, M.T. Catalysis Today, (1998) 42, 399.

21 Sénèque, O., Campion, M., Giorgi, M., Mest, Y.L. and Reinaud, O. (2004) European Journal of Inorganic Chemistry, 1817-1826.

22 Lejeune, M., Sémeril, D., Jeunesse, C., Matt, D., Peruch, F., Lutz, P.J. and Ricard, L. (2004) Chemistry - A European Journal, 10, 5354-5360.

23 Engeldinger, E., Armspach, D., Matt, D., Jones, P.G. and Welter, R. (2002) Angewandte Chemie - International Edition, 41, 2593-2596.

24 Hammes, B.S., Ramos-Maldonado, D., Yap, G.P.A., Liable-Sands, L., Rheingold, A.L., Young, V.G., Jr and Borovik, A.S. (1997) Inorganic Chemistry, 36, 3210-3211.

25 Vahrenkamp, H. (1999) Accounts of Chemical Research, 32, 589-596.
26 (a) Kitayima, N. and Tolman, W.B. (1995) Progress in Inorganic Chemistry, 43, 419-531. (b) Trofimenko, S. (1999) Scorpionates: The Coordination Chemistry of Polypyrazolylborate Ligands, Imperial College Press, London U.K.

27 Marty, M., Clyde-Watson, Z., Twyman, L.J., Nakash, M. and Sanders, J.K.M. (1998) Chemical Communications, 2265-2266.

28 Rohde, J.-U., In, J.-H., Lee, M.H., Brennessel, W.W., Bukowski, M.R., Stubna, A., Münck, E., Nam, W. and Que, L., Jr (2003) Science, 299, 1037-1039.

29 Ooi, T., Kondo, Y. and Maruoka, K. (1998) Angewandte Chemie - International Edition, 37, 3039-3041.

30 Yandulov, D.V. and Schrock, R.R. (2003) Science, 301, 76-83.

31 Castro-Rodriguez, I., Nakai, H., Zakharov, L., Rheingold, A.L. and Meyer, K. (2004) Science, 305, 1757-1759.

32 Ruf, M. and Vahrenkamp, H. (1996) Inorganic Chemistry, 35, 6571-6578.

33 Slagt, V.F., Reek, J.N.H., Cramer, P.C.J. and van Leeuwen P.W.N.M. (2001) Angewandte Chemie - International Edition, 40, 4271-4274.

34 (a) Breslow, R. (1995) Accounts of Chemical Research, 28, 146-153. (b) Breslow, R. and Dong, S. Chem. Rev., (1998) 98, 1997-2011.

35 Seneque, O., Rager M.-N. Giorgi, M. and Reinaud, O. (2001) Journal of the American Chemical Society, 123, 8442-8443.

36 Fontecha, J.B., Goetz, S. and McKee, V. (2002) Angewandte Chemie - International Edition, 41, 4553-4556.

$37 \mathrm{Du}$ Bois, J., Mizoguchi, T.J. and Lippard, S.J. (2000) Coordination Chemistry Reviews, 200-202, 443-485.

38 Kersting, B. (2004) Zeitschrift fur Anorganische und Allgemeine Chemie, 630, 765-780.

39 Kersting, B., Steinfeld, G., Fritz, T. and Hausmann, J. (1999) European Journal of Inorganic Chemistry, 2167-2172.

40 (a) Klingele, M.H. and Kersting, B. (2001) Zeitschrift fur Naturforschung, 56b, 437-439. (b) Klingele, M.H., Steinfeld, G. 
and Kersting, B. (2001) Zeitschrift fur Naturforschung, 56b, 901-907.

41 Kersting, B. and Steinfeld, G. (2001) Chemical Communications, 1376-1377.

42 Gressenbuch, M., Lozan, V., Steinfeld, G. and Kersting, B. (2005) European Journal of Inorganic Chemistry, 2223-2234.

43 Käss, S., Gregor, T. and Kersting, B. (2006) Angewandte Chemie - International Edition, 45, 101-104.

44 Gregor, T., Weise, C.F., Lozan, V. and Kersting, B. (2007) Synthesis, 3706-3712.

45 Gressenbuch, M. (2007) Ph.D. Thesis, Universität Leipzig.

46 Siedle, G. and Kersting, B. (2003) Zeitschrift fur Anorganische und Allgemeine Chemie, 629, 2083-2090.

47 Gressenbuch, M. and Kersting, B. (2007) European Journal of Inorganic Chemistry, 90-102.

48 Branscombe, N.D.J., Atkins, A.J., MarinBecerra A., McInnes, E.J.L., Mabbs, F.E., McMaster, J. and Schröder, M. (2003) Chemical Communications, 1098-1099.

49 Brooker, S. (2001) Coordination Chemistry Reviews, 222, 33-56.

50 Journaux, Y., Glaser, T., Steinfeld, G., Lozan, V. and Kersting, B. (2006) Dalton Transactions, 1738-1748.

51 Lozan, V. and Kersting, B. (2005) European Journal of Inorganic Chemistry, 504-512.

52 Kersting, B. and Steinfeld, G. (2002) Inorganic Chemistry, 41, 1140-1150.

53 Harding, C.J., McKee, V., Nelson, J. and Lu, Q. (1993) Journal of the Chemical Society, Chemical Communications, 1768-1770.

54 Kersting, B. (2001) Angewandte Chemie International Edition, 40, 3988-3990.

55 Barefield, E.K., Freeman, G.M. and Van Derveer D.G. (1986) Inorganic Chemistry, 25, 552-558.

56 Fritz, T., Steinfeld, G., Käss, S. and Kersting, B. (2006) Dalton Transactions, 3812-3821.
57 Hausmann, J., Käss, S., Kersting, B., Klod, S. and Kleinpeter, E. (2004) European Journal of Inorganic Chemistry, 4402-4411.

58 Smithrud, D.B., Sanford, E.M., Chao, I., Ferguson, S.B., Carcanague, D.R., Evanseck, J.D., Houk, K.N. and Diederich, F. (1990) Pure and Applied Chemistry, 62, 2227-2236.

59 Hausmann, J. (2001) Diplomarbeit, Universität Freiburg.

60 Engeldinger, E., Armspach, D., Matt, D., Jones, P.G. and Welter, R. (2002) Angewandte Chemie - International Edition, 41, 2593-2596.

61 Hausmann, J., Lozan, V., Klingele, M.H., Steinfeld, G., Siebert, D., Journaux, Y., Girerd, J.J. and Kersting, B. (2004) Chemistry - A European Journal, 10, 1716-1728.

62 Journaux, Y., Hausmann, J., Lozan, V. and Kersting, B. (2006) Chemical Communications, 83-84.

63 Steinfeld, G., Lozan, V. and Kersting, B. (2003) Angewandte Chemie - International Edition, 42, 2261-2263.

64 Lozan, V. and Kersting, B. unpublished results.

65 Lozan, V. and Kersting, B. (2007) European Journal of Inorganic Chemistry, 1436-1443.

66 Lozan, V. and Kersting, B. (2006) Inorganic Chemistry, 45, 5630-5634.

67 Hollemann, A.F. and Wiberg, E. (1985) Lehrbuch der Anorganischen Chemie, 91-100 edn, Walter de Gruyter, Berlin, pp. 557-559.

68 Meyer, E.A., Castellano, R.K. and Diederich, F. (2003) Angewandte Chemie International Edition, 115, 1244-1287.

69 Steinfeld, G. and Kersting, B. (2009) Zeitschrift für Anorganische und Allgemeine Chemie, in press.

70 Rideout, D.C. and Breslow, R. (1980) Journal of the American Chemical Society, 102, 7816-7817.

71 Kang, J. and Rebek, J., Jr (1997) Nature, 385, 50-52.

72 Kusukawa, T., Yoshizawa, M. and Fujita, M. (2002) Angewandte Chemie International Edition, 41, 1403-1405. 
